\title{
Determination of Ultratrace Level 135Cs and 135Cs/137Cs Ratio in Small Volume Seawater by Chemical Separation and Thermal Ionization Mass Spectrometry
}

\author{
Zhu, Liuchao; Xu, Changkun; Hou, Xiaolin; Qiao, Jixin; Zhao, Yonggang; Liu, Guorong
}

Published in:

Analytical Chemistry

Link to article, DOI:

10.1021/acs.analchem.0c00688

Publication date:

2020

Document Version

Publisher's PDF, also known as Version of record

Link back to DTU Orbit

Citation (APA):

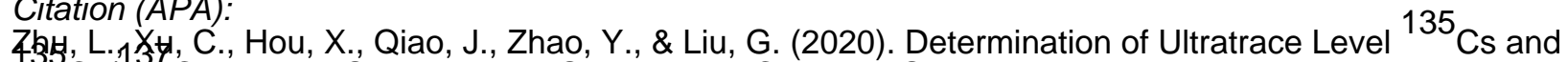
$\mathrm{Cs} /{ }^{3}$ Cs Ratio in Small Volume Seawater by Chemical Separation and Thermal lonization Mass Spectrometry. Analytical Chemistry, 92(9), 6709-6718. https://doi.org/10.1021/acs.analchem.0c00688

\section{General rights}

Copyright and moral rights for the publications made accessible in the public portal are retained by the authors and/or other copyright owners and it is a condition of accessing publications that users recognise and abide by the legal requirements associated with these rights.

- Users may download and print one copy of any publication from the public portal for the purpose of private study or research.

- You may not further distribute the material or use it for any profit-making activity or commercial gain

- You may freely distribute the URL identifying the publication in the public portal 


\title{
Determination of Ultratrace Level ${ }^{135} \mathrm{Cs}$ and ${ }^{135} \mathrm{Cs} /{ }^{137} \mathrm{Cs}$ Ratio in Small Volume Seawater by Chemical Separation and Thermal Ionization Mass Spectrometry
}

\author{
Liuchao Zhu, Changkun Xu, Xiaolin Hou,* Jixin Qiao, Yonggang Zhao, and Guorong Liu
}

Cite This: Anal. Chem. 2020, 92, 6709-6718

Read Online

ACCESS | Llll Metrics \& More | 国 Article Recommendations | st Supporting Information

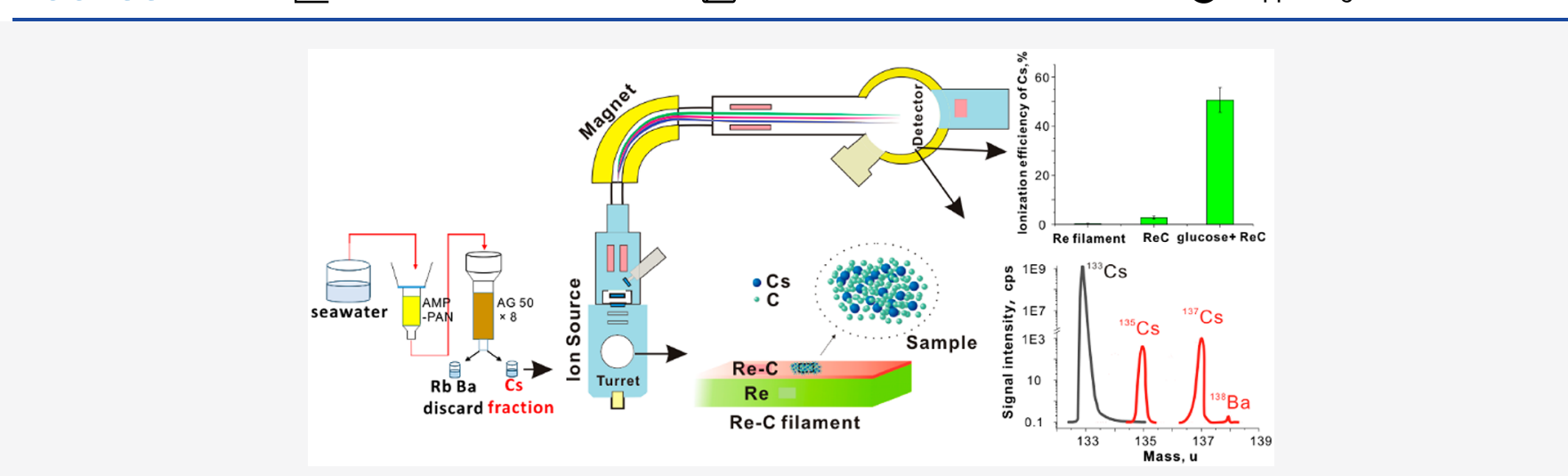

ABSTRACT: The atomic ratio of ${ }^{135} \mathrm{Cs} /{ }^{137} \mathrm{Cs}$ is a powerful fingerprint for distinguishing the source terms of radioactive contamination and tracing the circulation of water masses in the ocean. However, the determination of the ${ }^{135} \mathrm{Cs} /{ }^{137} \mathrm{Cs}$ ratio is very difficult due to the ultratrace level of ${ }^{135} \mathrm{Cs}\left(<0.02 \mathrm{mBq} / \mathrm{m}^{3}\right)$ and ${ }^{137} \mathrm{Cs}\left(<2 \mathrm{~Bq} / \mathrm{m}^{3}\right)$ in the ordinary seawater samples. In this work, a sensitive method was developed for determination of ${ }^{135} \mathrm{Cs}$ concentration and ${ }^{135} \mathrm{Cs} /{ }^{137} \mathrm{Cs}$ ratio in seawater using chemical separation combined with thermal ionization mass spectrometry (TIMS) measurement. Cesium was first preconcentrated from seawater using ammonium molybdophosphate-polyacrylonitrile column chromatography and then purified using cation exchange chromatography to remove the interferences. With this method, decontamination factors of $6.0 \times 10^{6}$ for barium and 1800 for rubidium and a chemical yield of more than $60 \%$ for cesium were achieved. By using glucose as an activator, the ionization efficiency of cesium was significantly improved to $50.6 \%$, and a constant high current of $\mathrm{Cs}^{+}(20 \mathrm{~V})$ can be maintained for more than 180 min, which ensures sensitive and reliable measurement of low level ${ }^{135} \mathrm{Cs}$ and ${ }^{137} \mathrm{Cs}$. Detection limits of $4.0 \times 10^{-17} \mathrm{~g} / \mathrm{L}$ for both ${ }^{135} \mathrm{Cs}$ and ${ }^{137} \mathrm{Cs}$ for $200 \mathrm{~mL}$ seawater were achieved, which enables the accurate determination of ${ }^{135} \mathrm{Cs}$ concentration and ${ }^{135} \mathrm{Cs} /{ }^{137} \mathrm{Cs}$ ratio in a small volume of seawater samples $(<200 \mathrm{~mL})$. The developed method has been validated by analysis of seawater reference material IAEA-443. Seawater samples collected from the Greenland Sea, Baltic Sea, and Danish Straits have been successfully analyzed for ${ }^{135} \mathrm{Cs}$ concentrations and ${ }^{135} \mathrm{Cs} /{ }^{137} \mathrm{Cs}$ ratios, and the results showed that ${ }^{135} \mathrm{Cs}$ concentrations in the seawater of the Baltic Sea is much higher than that in the Greenland Sea, which is attributed to the high deposition of Chernobyl accident derived radiocesium in the Baltic Sea region.

$\mathrm{R}$ adiocesium $\left({ }^{134} \mathrm{Cs},{ }^{135} \mathrm{Cs}\right.$, and $\left.{ }^{137} \mathrm{Cs}\right)$ was produced and released to the environment by human nuclear activities, such as nuclear weapon tests, nuclear accidents, spent nuclear fuel reprocessing, and operation of nuclear reactors. Due to the high fission yield (6.22\% for ${ }^{235} \mathrm{U}$ thermal neutron fission), more than $1400 \mathrm{PBq}$ of ${ }^{137} \mathrm{Cs}$ has been released into the environment. ${ }^{1}{ }^{137} \mathrm{Cs}$ is therefore one of the most important radionuclides in view of the radiation impact of human nuclear activities on the eco-system. Although ${ }^{134} \mathrm{Cs}$ can be also produced through fission reactions of uranium and plutonium with a very low independent fission yield $\left(1.2 \times 10^{-5} \%\right.$ for ${ }^{235} \mathrm{U}$ ), it is mainly produced by neutron activation of ${ }^{133} \mathrm{Cs}$, which is a fission product, and stable isotopes of cesium presented in reactor materials and nuclear fuel as an impurity. ${ }^{135} \mathrm{Cs}$ is also a fission product of uranium and plutonium, but its fission yield varies with neutron flux and irradiation time. Due to the source specific value, the ${ }^{134} \mathrm{Cs} /{ }^{137} \mathrm{Cs}$ ratio has been successfully used as a tracer for source identification ${ }^{2,3}$ and

Received: February 16, 2020

Accepted: April 9, 2020

Published: April 9, 2020 
investigation of geochemical processes, such as sedimentation rate, ${ }^{4}$ transport pathway of reprocessing discharge labeled water from the North Sea to the Arctic and Greenland Sea and corresponding transit times, ${ }^{5}$ the sources and contribution of the Fukushima derived radioactive substances in the ocean, and atmospheric deposition. ${ }^{6}$ However, the relative short halflife of ${ }^{134} \mathrm{Cs}(2.06 \mathrm{y})$ makes the ${ }^{134} \mathrm{Cs} /{ }^{137} \mathrm{Cs}$ ratio less applicable after several years post release. ${ }^{135} \mathrm{Cs}$, a long-lived radiocesium with a half-life of $2.3 \times 10^{6}$ years, provides an option to replace ${ }^{134} \mathrm{Cs}$ as an environmental tracer. ${ }^{135} \mathrm{Xe}$ is the decay precursor of ${ }^{135} \mathrm{Cs}$ in its fission production from uranium and plutonium; it has a very large neutron capture cross section $\left(2.6 \times 10^{6} \mathrm{~b}\right)$ and is considered a neutron poison in the nuclear reactor. Therefore, the production yield of ${ }^{135} \mathrm{Cs}$ is highly dependent on the neutron flux and irradiation time. Consequentially, the ${ }^{135} \mathrm{Cs} /{ }^{137} \mathrm{Cs}$ atomic ratio is a specific and unique feature of its source. The ${ }^{135} \mathrm{Cs} /{ }^{137} \mathrm{Cs}$ atomic ratio in the global fallout of nuclear weapons tests was reported to be $0.92 \pm 0.5^{7}$ (refer to year 1962), while much lower ${ }^{135} \mathrm{Cs} /{ }^{137} \mathrm{Cs}$ ratios of $0.29 \pm 0.04$ (refer to April 1986) in the Chernobyl accident release $^{8}$ and $0.333-0.375$ (refer to March 11, 2011) in the Fukushima accident release 9 were reported. After the Fukushima Diichi nuclear power plant accident, the ${ }^{135} \mathrm{Cs} /{ }^{137} \mathrm{Cs}$ ratios in various environmental samples such as soil, lichen, moss, rice, mushroom, soybean, bark, and sediment ${ }^{10-17}$ and waste such as spent Cs adsorbents ${ }^{18}$ were determined to assess the contamination level and identify the sources of ${ }^{137} \mathrm{Cs}$ (the damaged reactors or the spent fuel pools). However, less work has been dedicated to the determination of ${ }^{135} \mathrm{Cs} /{ }^{137} \mathrm{Cs}$ in seawater samples, especially in seawater without direct contamination. The only one data of ${ }^{135} \mathrm{Cs} /{ }^{137} \mathrm{Cs}$ in a heavily contaminated Irish seawater (IAEA443) was reported to be $1.22 \pm 0.11$ (refer to first Jan 2015). ${ }^{8}$ Cesium is considered a conservative element in the ocean; large amount of radiocesium has been discharged from reprocessing plants and the Fukushima accident to the seas, and the air releases of radiocesium from the Chernobyl and Fukushima accidents were also deposited and transported to the seas. The ${ }^{135} \mathrm{Cs} /{ }^{137} \mathrm{Cs}$ ratios in seawater provide an excellent tracer in oceanographic studies.

Although the determination of ${ }^{135} \mathrm{Cs}$ in nuclear waste using neutron activation analysis (NAA) was reported in $1973,{ }^{19}$ the determination of ${ }^{135} \mathrm{Cs}$ in environmental samples became possible only in recent years by mass spectrometry due to its low concentration. Sector field inductively coupled plasmamass spectrometry (SF-ICP-MS), ${ }^{20,21}$ electrothermal vaporization-inductively coupled plasma-mass spectrometry (ETVICP-MS ), ${ }^{22}$ triple quadrupole inductively coupled plasma-mass spectrometry (ICP-QQQ-MS), ${ }^{6,9,10}$ resonance ionization mass spectrometry (RIMS), ${ }^{23}$ and thermal ionization mass spectrometry (TIMS) ${ }^{7,24-29}$ have been used for this purpose. Due to the serious isobaric interference of ${ }^{135} \mathrm{Ba}$ and polyatomic interference (e.g., ${ }^{95} \mathrm{Mo}^{40} \mathrm{Ar}^{+},{ }^{97} \mathrm{Mo}^{40} \mathrm{Ar}^{+},{ }^{119} \mathrm{Sn}^{16} \mathrm{O}^{+}$, $\left.{ }^{121} \mathrm{Sn}^{16} \mathrm{O}^{+}\right)$, high decontamination factors for $\mathrm{Ba}$ and other interfering elements are needed prior to the spectrometric measurement. Due to the high elimination of Ba using a dynamic reaction cell and significant improvement of abundance sensitivity, ICP-QQQ-MS has been successfully applied for measurement of ${ }^{135} \mathrm{Cs} /{ }^{137} \mathrm{Cs}$ ratios in various environmental samples. However, due to the very low ${ }^{135} \mathrm{Cs}$ concentration $\left(<5 \times 10^{-16} \mathrm{~g} / \mathrm{L}\right)$ in ordinary seawater, up to 45 $\mathrm{L}$ of seawater is needed for the determination using this method, which makes the sampling difficult and chemical separation time-consuming. TIMS is a sensitive method for measurement of low-level radionuclides, the different behaviors of $\mathrm{Cs}$ and $\mathrm{Ba}$ on the evaporation and ionization in TIMS make it easy to eliminate the interference of ${ }^{135} \mathrm{Ba}$. However, the low ionization efficiency of $\mathrm{Cs}$ and serious suppression effect of $\mathrm{Rb}$ on the ionization of Cs in TIMS seriously limit the sensitive measurement of ${ }^{135} \mathrm{Cs}$ in environmental samples. This work aims to develop a sensitive and reliable method for determination of ultra-low-level ${ }^{135} \mathrm{Cs}$ and ${ }^{137} \mathrm{Cs}$ in small volumes of seawater samples, in order to apply them as tracers for oceanographic studies. Efforts were mainly devoted to effective removal of $\mathrm{Rb}$ and sensitive TIMS measurement of ${ }^{135} \mathrm{Cs}$ and ${ }^{137} \mathrm{Cs}$ by improving the ionization efficiency of Cs on the target.

\section{EXPERIMENTAL SECTION}

Reagent and Material. All reagents used in this study, including $\mathrm{HNO}_{3}, \mathrm{HCl}, \mathrm{NH}_{4} \mathrm{NO}_{3}$ and $\mathrm{NH}_{3} \cdot \mathrm{H}_{2} \mathrm{O}$, benzene, and graphite were of analytical reagent grade. Ultrapure water (18.2 $\mathrm{M} \Omega \mathrm{cm}$ ) produced by Sartorius water purification system (Arium pro VF) was applied for dissolution and dilution of reagents. In-house purified $\mathrm{HNO}_{3}$ by a distillation system (Savillex DST-1000, USA) was employed for the final elution of cesium from a cation exchange resin column and dissolution of the final solution prior to TIMS measurement. Ammonium molybdophosphate-polyacrylonitrile (AMP-PAN, 60-100 $\mu \mathrm{m}$ ) resin and strong acidic cation exchange resin (AG 50W$\times 8, \mathrm{H}^{+}$form, analytical grade, 100-200 mesh) used for separation and purification of cesium were purchased from Triskem International and Bio-Rad Laboratories, respectively. $\mathrm{D}(+)$-Glucose, (analytical reagent grade) was purchased from VWR International, LLC, and prepared in a $100 \mathrm{~g} / \mathrm{L}$ solution using deionized water $(18.2 \mathrm{M} \Omega \mathrm{cm})$

Reference materials IAEA-375 (soil collected from Novozybkov, Bryansk, Russia in 1990) and IAEA-443 (Irish seawater sampled in 1993) were provided by the International Atomic Energy Agency (IAEA). Seawater samples were collected from the Danish Straits (Møn, Sundet, Kattegat, and Hesselø), the Baltic Sea, and the west coast of Greenland in different sampling campaigns. The sampling sites are shown in Figure S1. These water samples were filtered through a 0.45 $\mu \mathrm{m}$ membrane, acidified to $\mathrm{pH} 2$ using $\mathrm{HNO}_{3}$, and stored in a polyethylene container for shipping to a laboratory for analysis.

Instrumentation. The measurement of cesium isotopes was implemented by Triton Plus TIMS (Thermal Fisher Science, USA), which is equipped with nine Faraday cups and five ion counters (IC). There are two retarding potential quadrupoles (RPQ) located at the front of the central IC1 and high mass position IC5, which can improve the abundance sensitivity to less than $4 \times 10^{-10}$ for the ${ }^{135} \mathrm{Cs} /{ }^{133} \mathrm{Cs}$ ratio by suppressing the tailing effect of a strong ${ }^{133} \mathrm{Cs}$ signal. Due to the specific collector configuration, it was hindered to determine ${ }^{135} \mathrm{Cs}$, ${ }^{137} \mathrm{Cs}$, and ${ }^{133} \mathrm{Cs}$ simultaneously, so peakjumping mode was employed to perform the measurement of ${ }^{135} \mathrm{Cs} /{ }^{133} \mathrm{Cs},{ }^{137} \mathrm{Cs} /{ }^{133} \mathrm{Cs}$, and ${ }^{135} \mathrm{Cs} /{ }^{137} \mathrm{Cs}$ atomic ratios in this study. In order to decrease the scattering influence of ${ }^{133} \mathrm{Cs}$ in the ion counter, ${ }^{133} \mathrm{Cs}$ ions were measured by a Faraday cup. For low-level seawater samples, an integration time of $8 \mathrm{~s}$ was selected to improve the statistics of counts of these ions $\left({ }^{135} \mathrm{Cs}^{+}\right.$and $\left.{ }^{137} \mathrm{Cs}^{+}\right)$and therefore their measurement precision. Auto tune was conducted for optimization of the signals of 


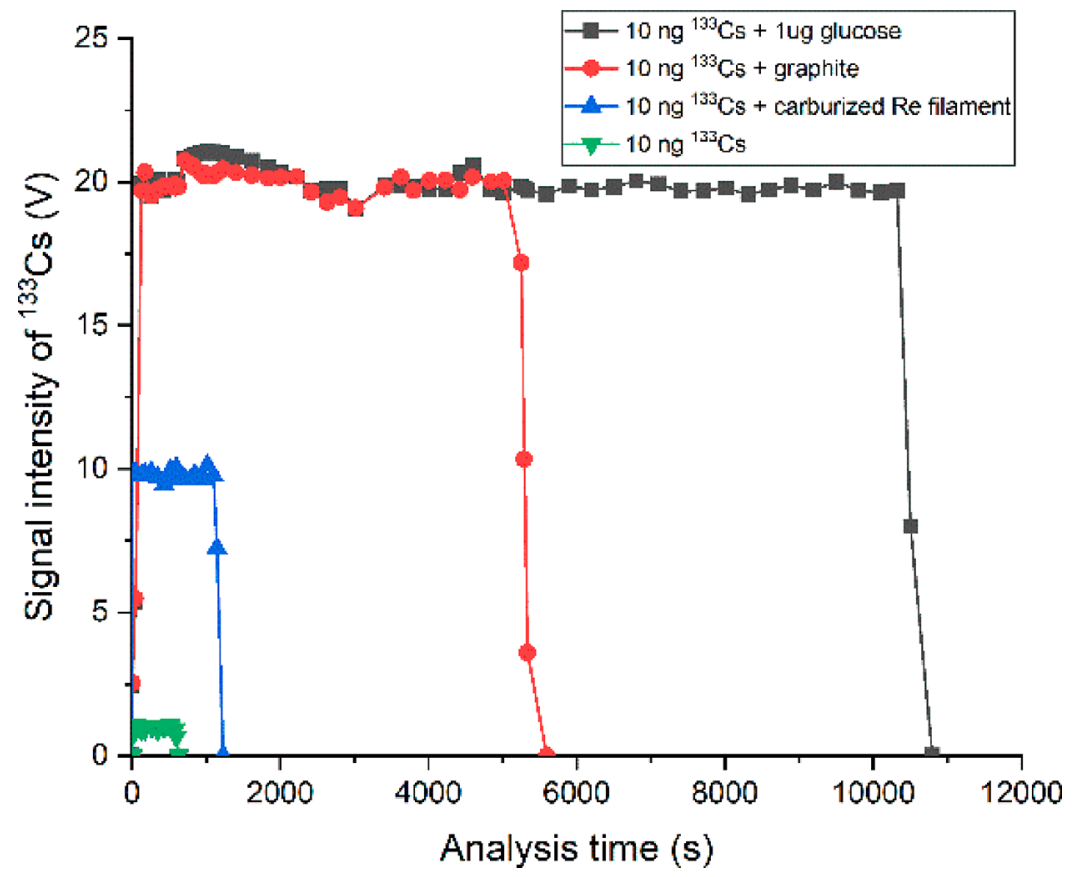

Figure 1. Intensity and extended time of $\mathrm{Cs}^{+}$ion signal of Cs target prepared using different methods in TIMS measurement. The target was prepared using $10 \mathrm{ng}$ of cesium and heated at $400 \mathrm{~mA}$ for evaporation: One sample of $10 \mathrm{ng}$ of Cs was directly loaded onto the Re filament. One sample was loaded on a carburized Re filament, and the other two samples were prepared by mixing graphite slurry or $1 \mu \mathrm{g}$ of glucose solution as an activator with $10 \mathrm{ng}$ of $\mathrm{Cs}$ and loaded on the carburized Re filament.

${ }^{135} \mathrm{Cs}$ and ${ }^{137} \mathrm{Cs}$ after the signal of ${ }^{133} \mathrm{Cs}$ was increased to $2 \mathrm{~V}$. Seawater samples were measured at an intensity of about $20 \mathrm{~V}$ for ${ }^{133} \mathrm{Cs}$, which corresponds to a filament current of about 940 $\mathrm{mA}$. Parameters affecting the measurement of ${ }^{135} \mathrm{Cs}$ and ${ }^{137} \mathrm{Cs}$ such as filament type and heating current of filament were investigated and optimized.

Investigations on the Effects of Activators and Heating Current on Ionization Efficiency of Cs. Ten nanograms of stable ${ }^{133} \mathrm{Cs}$ (in a single element standard solution) and several micrograms of graphite or glucose solution (D-glucose of $100 \mathrm{~g} / \mathrm{L}$ prepared using deionized water) were mixed and loaded on Re filament and then evaporated to dryness at a certain current. The ionization efficiency of ${ }^{133} \mathrm{Cs}$ was measured using the central Faraday cup in total evaporation (TE) mode (nearly all ions would be collected until the sample was completely consumed). The ionization efficiency was presented and calculated as a ratio of the number of measured $\mathrm{Cs}^{+}$ions to the number of cesiums loaded on the filament. The effects of activators and heating current, as well as carburization of the Re filament on the ionization efficiency, were evaluated.

Investigations on the Influence of $\mathrm{Rb}$ and $\mathrm{Ba}$ on the Measurement of Cesium Isotopes. Ten nanograms of stable ${ }^{133} \mathrm{Cs}$ was mixed with different amounts of $\mathrm{Rb}$ ranging from $10 \mathrm{ng}$ to $1 \mu \mathrm{g}$ and then loaded on the Re filament. The ionization efficiency of ${ }^{133} \mathrm{Cs}$ was measured to evaluate the influence of the amount of $\mathrm{Rb}$ on the measurement of ${ }^{135} \mathrm{Cs}$.

Ten nanograms of stable ${ }^{133} \mathrm{Cs}$ was mixed with different amounts of Ba ranging from $0.1 \mathrm{ng}$ to $100 \mathrm{ng}$ and loaded on the Re filament. The variation of signal intensities of ${ }^{133} \mathrm{Cs}$ and ${ }^{135} \mathrm{Ba}$ ions with the filament current was measured to investigate the influence of $\mathrm{Ba}$ on the measurement of ${ }^{135} \mathrm{Cs}$.

Chemical Separation of Cesium from Seawater. An AMP-PAN resin was used for preconcentration of Cs from seawater. A total of $200 \mathrm{~mL}$ of seawater was first acidified using
$\mathrm{HNO}_{3}$ and adjusted to $1.0 \mathrm{M} \mathrm{HNO}_{3}$, which was loaded onto a $2 \mathrm{~mL}$ AMP-PAN column $(\varphi 7 \mathrm{~mm} \times 5 \mathrm{~cm})$. After rinsing with $45 \mathrm{~mL}$ of $1.0 \mathrm{M} \mathrm{HNO}_{3}$ and $15 \mathrm{~mL}$ of ultrapure $\mathrm{H}_{2} \mathrm{O}$, the column was rinsed using $200 \mathrm{~mL}$ of $0.1 \mathrm{M} \mathrm{NH}_{4} \mathrm{NO}_{3}$ to remove $\mathrm{Rb}$; finally, $10 \mathrm{~mL}$ of $1.5 \mathrm{M} \mathrm{NH}_{3} \cdot \mathrm{H}_{2} \mathrm{O}$ was employed to elute Cs from the AMP-PAN column.

The eluate of $1.5 \mathrm{M} \mathrm{NH}_{3} \cdot \mathrm{H}_{2} \mathrm{O}$ was directly loaded onto a 10 $\mathrm{mL}$ cation exchange column $\left(\mathrm{AG} 50 \mathrm{~W}-\times 8, \mathrm{H}^{+}\right.$form, $\varphi 1.0 \mathrm{~cm}$ $\times 20 \mathrm{~cm}$ ), which was preconditioned with $50 \mathrm{~mL}$ of $5.0 \mathrm{M}$ $\mathrm{HNO}_{3}, 20 \mathrm{~mL}$ of ultrapure $\mathrm{H}_{2} \mathrm{O}$, and $20 \mathrm{~mL}$ of $1.5 \mathrm{M} \mathrm{NH}_{3}$. $\mathrm{H}_{2} \mathrm{O}$. The column was rinsed with $50 \mathrm{~mL}$ of $1.5 \mathrm{M} \mathrm{NH}_{3} \cdot \mathrm{H}_{2} \mathrm{O}$, $20 \mathrm{~mL}$ of ultrapure $\mathrm{H}_{2} \mathrm{O}$, and $220 \mathrm{~mL}$ of $0.5 \mathrm{M} \mathrm{HNO}_{3}$. Finally, $100 \mathrm{~mL}$ of $0.5 \mathrm{M} \mathrm{HNO}_{3}$ (purified by distillation) was employed to elute Cs from the AG 50W- $\times 8$ column. The eluate was evaporated to dryness and redissolved with a few microliters of $2 \% \mathrm{HNO}_{3}$ for TIMS measurement of ${ }^{135} \mathrm{Cs}$ and ${ }^{137} \mathrm{Cs}$. The diagram of the analytical procedure is shown in Figure S2.

Soil reference material (IAEA-375) of $0.5 \mathrm{~g}$ was weighed to a beaker and ashed in a muffle oven at $450{ }^{\circ} \mathrm{C}$ for $8 \mathrm{~h}$ to decompose the organic matter, then the soil sample was digested with $20 \mathrm{~mL}$ of aqua regia at $180{ }^{\circ} \mathrm{C}$ for $4 \mathrm{~h}$. After filtration, the leachate was adjusted to $1.0 \mathrm{M} \mathrm{HNO}_{3}$, and cesium was separated using the same procedure as for seawater using AMP-PAN and AG 50W- $\times 8$ columns.

\section{RESULTS AND DISCUSSION}

Selection of Optimal Activator for lonization of Cs in TIMS. Our preliminary experiment showed that the intensity of the $\mathrm{Cs}^{+}$signal was very weak $(<1 \mathrm{~V})$, and the cesium loaded on the ordinary Re filament was quickly consumed. A total of $10 \mathrm{ng}$ of cesium on the Re filament was used in about $10 \mathrm{~min}$. The total ionization efficiency of cesium was estimated to be only $0.5 \%$ (Figure 1 ). The very low ionization efficiency of cesium caused unstable and low measurement sensitivity of 
${ }^{135} \mathrm{Cs}$ and ${ }^{137} \mathrm{Cs}$. It was reported that carburization of the filament could improve the ionization efficiency of analytes in TIMS measurement. ${ }^{30}$ Our experimental results (Figure 1) indicate that carburization of the Re filament before loading the cesium sample can only increase the ionization efficiency to $2.8 \%$. However, by loading a mixture of the cesium sample solution with a graphite slurry on the Re filament, the ionization efficiency of cesium was significantly improved by a factor of 5, up to $12.9 \%$. Mixing the sample with a glucose solution $(1 \mu \mathrm{g})$ further improved the ionization efficiency of cesium to $26.7 \%$ (Figure 1), showing an excellent feature for enhancing the $\mathrm{Cs}^{+}$ionization. Although a similar high current of $\mathrm{Cs}^{+}$of $20 \mathrm{~V}$ was achieved for both graphite and glucose as an activator, the sample that used glucose as an activator showed much a longer term of stable $\mathrm{Cs}^{+}$ion current, up to $180 \mathrm{~min}$ compared to about $85 \mathrm{~min}$ for graphite as an activator (Figure 1).

The amount of glucose used as an activator has shown a significant influence on the ionization efficiency of cesium. For a total load of $10 \mathrm{ng}$ of ${ }^{133} \mathrm{Cs}$, the ionization efficiency of Cs increased exponentially with an amount of glucose less than 1000 ng (Figure 2); a relative constant ionization efficiency

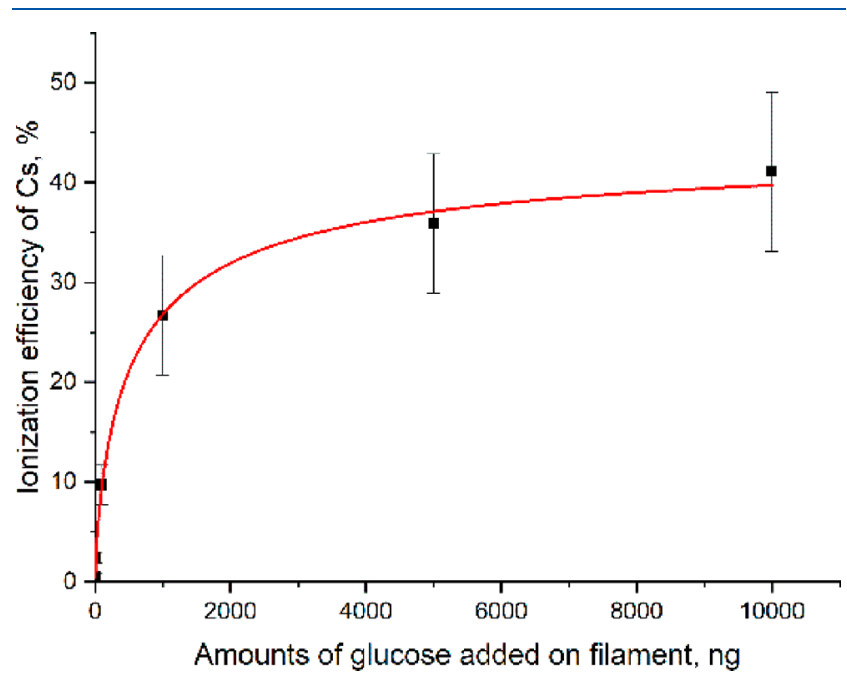

Figure 2. Variation of ionization efficiencies of cesium (10 ng) with the amounts of glucose added on the filament as an activator $(400 \mathrm{~mA}$ of heating current for sample evaporation, carburized Re filament was used for the experiment).

was obtained when the loaded amount of glucose was higher than $5.0 \mu \mathrm{g}$. With $10 \mu \mathrm{g}$ of glucose, the ionization efficiency of $10 \mathrm{ng}$ of cesium was observed to be $41 \%$, which is more than 80 times higher than that without activator. However, when more than $10 \mu \mathrm{g}$ of glucose was loaded with cesium (10 ng), the vacuum of the ionization chamber started to become worse, causing unstable signal intensity and consequently worsening analytical precision. Therefore, $10 \mu \mathrm{g}$ of glucose was selected for sample preparation on the filament in this work.

The improvement of ionization efficiency of the analyte by adding activators on the filament has been widely reported. For the measurement of ${ }^{135} \mathrm{Cs}$, silica gel $+\mathrm{H}_{3} \mathrm{PO}_{4}, \mathrm{TaCl}_{5}+\mathrm{H}_{3} \mathrm{PO}_{4}$, $\mathrm{Ta}_{2} \mathrm{O}_{5}$, graphite, and glucose have been applied as activators, ${ }^{14,16,28}$ and the highest ionization efficiency of $20.9 \%$ was reported by using graphite slurry. Our result using $10 \mu \mathrm{g}$ of glucose is more than 2 times higher than the reported value. It is not well understood how the activator can improve the ionization efficiency of cesium. Cesium is a volatile element; most cesium compounds (e.g., $\mathrm{CsNO}_{3}$ ) are easily vaporized or decomposed at relatively low temperatures. Addition of an activator can stabilize cesium by reducing the vaporization speed of cesium on the filament during the heating process. It was reported that carbon and uranium could form uranium carbide species ( $\mathrm{UC}$ or $\mathrm{UC}_{2}$ ) on the filament during heating, which significantly enhanced the ionization efficiency of uranium by hindering the formation of oxides as a volatile species such as $\mathrm{UO}^{+}$and $\mathrm{UO}_{2}{ }^{+31}$ As for cesium, a similar process might occur to form cesium carbide and significantly stabilize the cesium on the filament, which helps to produce a constantly high intensity $\mathrm{Cs}^{+}$ion beam during the thermal ionization process in TIMS. Carburized Re filament and graphite slurry can provide carbon to form such cesium carbide (surface binding), while glucose can react with a cesium sample more efficiently, thus to stabilize the cesium on the filament and improve the ionization efficiency of cesium.

Influence of Heating Current of the Filament for Sample Evaporation on the Ionization Efficiency of Cesium. Cesium solution with an activator loaded on the filament was first evaporated by heating the filament before measurement. The heating current might influence the quality of the Cs target prepared on the filament and therefore the ionization efficiency of cesium. Mixtures of $10 \mathrm{ng}$ of Cs with 10 $\mu \mathrm{g}$ of glucose were loaded onto both ordinary and carburized Re filaments; the samples on filaments were then evaporated at different heating currents for target preparation to investigate this effect. The experiment results (Figure 3) show that the

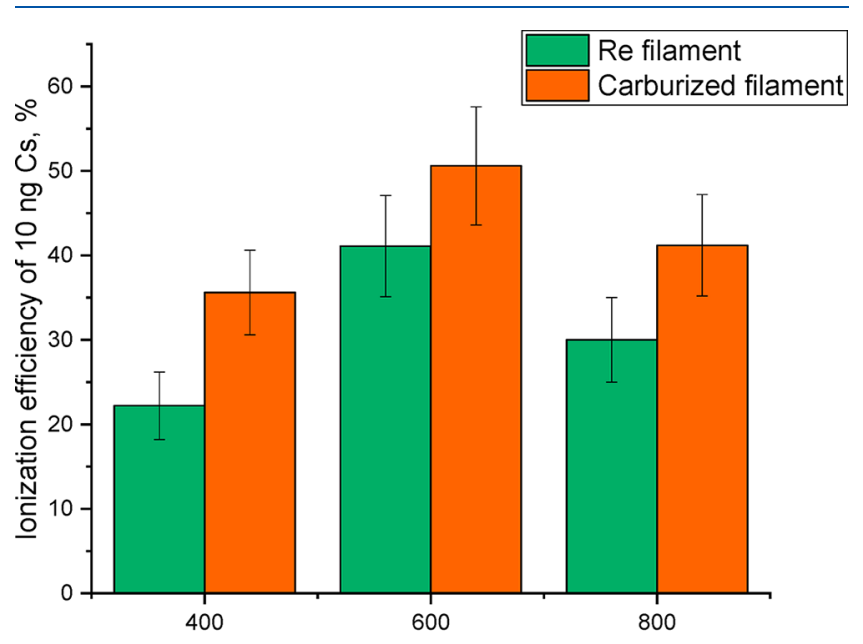

Heating current of sample preparation, $\mathrm{mA}$

Figure 3. Effect of heating current of the filament for sample evaporation on the ionization efficiency of cesium in the TIMS measurement $(10 \mathrm{ng}$ of cesium and $10 \mu \mathrm{g}$ of glucose solution were mixed and loaded onto the filament for target preparation).

highest ionization efficiencies of cesium (41.1\% and 50.6\%) were obtained for ordinary and carburized filaments when the sample was evaporated at a current of $600 \mathrm{~mA}$. This might be attributed to the low current being not sufficient to form stable cesium carbide compounds, while a higher current causes a loss of cesium during the evaporation process. It is noteworthy that relatively higher ionization efficiencies were always obtained using a carburized Re filament compared to an ordinary Re filament. 


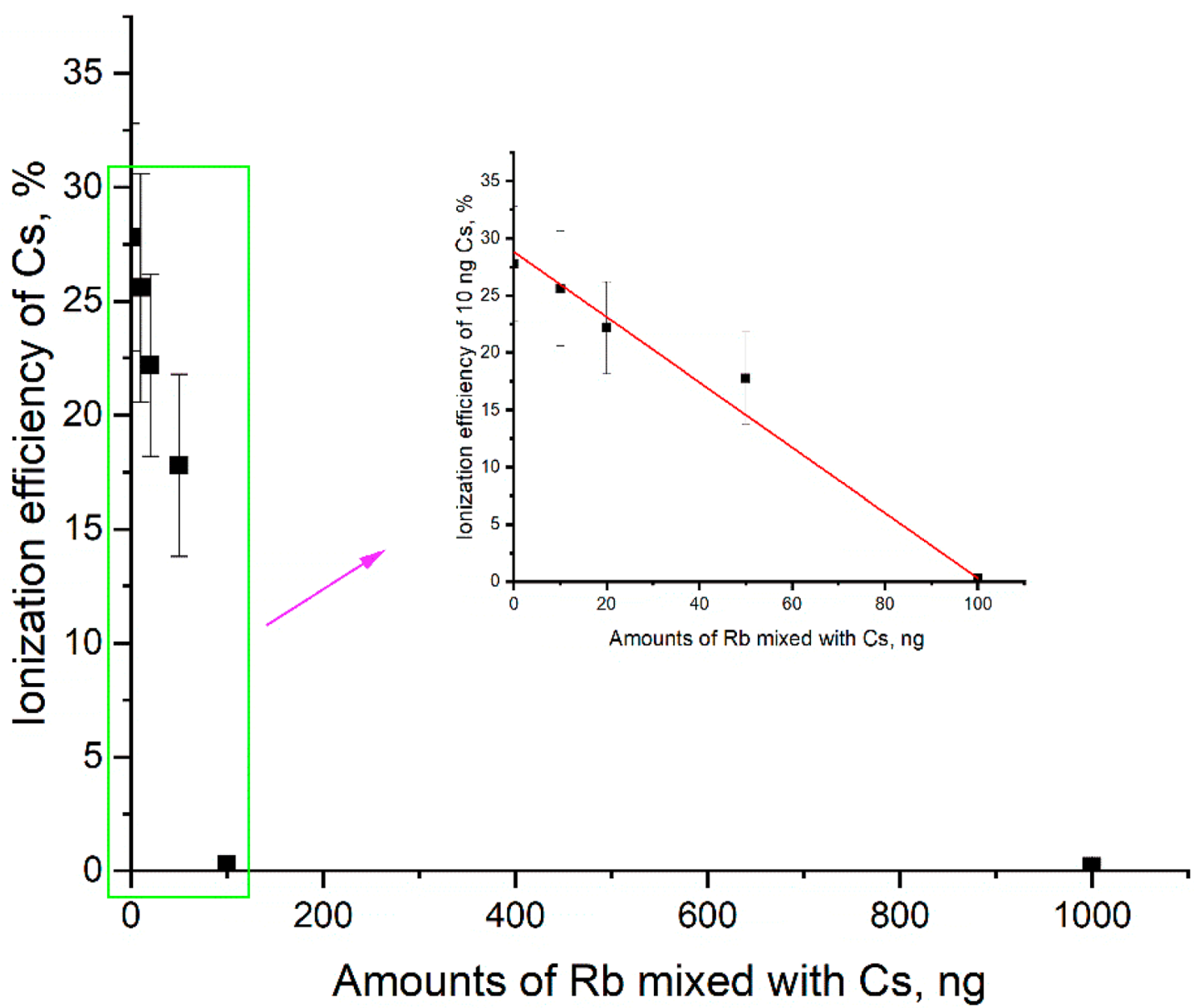

Figure 4. Variation of ionization efficiency of cesium with the amounts of $\mathrm{Rb}$ present on the filament (solution containing $10 \mathrm{ng}$ of cesium and 1.0 $\mu \mathrm{g}$ of glucose was evaporated on the Re filament at $600 \mathrm{~mA}$ of heating current for evaporation).

Type of Re Filament for Cs Isotopes Measurement. Both single and double filaments are used in TIMS for the isotopes measurement of different elements. The two models of filament were investigated for the measurement of ${ }^{135} \mathrm{Cs}$ by TIMS. Ten nanograms of stable ${ }^{133} \mathrm{Cs}, 1 \mathrm{ng}$ of stable $\mathrm{Ba}$, and $10 \mu \mathrm{g}$ of glucose solution were loaded on the filaments of single Re or double Re filaments; the intensities of the $\mathrm{Cs}^{+}$ion signal were measured with increased current on the filament. The results showed that for a carburized single Re filament, the intensity of the ${ }^{133} \mathrm{Cs}$ ion signal reached $20 \mathrm{~V}$ when the filament current was increased to $<950 \mathrm{~mA}$. Under this condition, the count rate at $\mathrm{m} / z 135$ was less than 0.5 cps. However, for double filaments, the ionization current on the filament has to be increased to more than $1300 \mathrm{~mA}$ for reaching $20 \mathrm{~V}$ for the signal intensity of ${ }^{133} \mathrm{Cs}$. Under this condition, the count rate of up to $5 \mathrm{cps}$ at $\mathrm{m} / z 135$ was observed. These results indicate that a higher temperature is required for ionization of cesium when employing a double filament, which caused an increased interference of $\mathrm{Ba}$ on the measurement of ${ }^{135} \mathrm{Cs}$, worsened the measurement accuracy of low-level ${ }^{135} \mathrm{Cs}$ in seawater samples and raised the detection limit of ${ }^{135} \mathrm{Cs}$. Therefore, the carburized single Re filament was employed for the measurement of ${ }^{135} \mathrm{Cs}$ and ${ }^{137} \mathrm{Cs}$ in this study.

Influence of $\mathrm{Rb}$ and $\mathrm{Ba}$ on the Measurement of Cesium Isotopes by TIMS. It has been reported that $\mathrm{Rb}$ can suppress the ionization of cesium in TIMS measurement due to its similar ionization potential $(3.89 \mathrm{eV}$ for Cs vs $4.18 \mathrm{eV}$ for $\mathrm{Rb}) .^{32}$ The experiment using $10 \mathrm{ng}$ of stable ${ }^{133} \mathrm{Cs}$ mixed with different amounts of $\mathrm{Rb}$ ( $10 \mathrm{ng}$ to $1000 \mathrm{ng}$ ) showed that the ionization efficiency of Cs decreased from $26.7 \%$ to less than $0.2 \%$ when the amount of $\mathrm{Rb}$ was increased from $10 \mathrm{ng}$ to $1000 \mathrm{ng}$ (Figure 4). When $20 \mathrm{ng}$ of $\mathrm{Rb}$ was presented in the sample, the ionization efficiency of Cs decreased by $10-20 \%$ compared to that without $\mathrm{Rb}$. However, if the amounts of $\mathrm{Rb}$ increased to $100 \mathrm{ng}$, ionization efficiency decreased almost 100 times. Since the concentration of $\mathrm{Rb}$ in the environmental samples is a few orders of magnitude higher than that of Cs, e.g., $0.27-0.55 \mathrm{ng} / \mathrm{mL}$ for $\mathrm{Cs}$ and $119-138 \mathrm{ng} / \mathrm{mL}$ for $\mathrm{Rb}$ in seawater, ${ }^{33,34}$ removal of $\mathrm{Rb}$ from cesium is important for the sensitive measurement of cesium isotopes by TIMS.

The major isobaric interference for measurement of ${ }^{135} \mathrm{Cs}$ in mass spectrometry is the isobar ${ }^{135} \mathrm{Ba}$ (natural abundance of $6.59 \%)$. Due to the significantly different first ionization potentials of cesium $(3.89 \mathrm{eV})$ and barium $(5.21 \mathrm{eV})$, cesium starts to be ionized at a filament current of only $800 \mathrm{~mA}$ and reaches $20 \mathrm{~V}$ at a current of $930 \mathrm{~mA}$, while Ba starts to be ionized at a filament current of more than $1200 \mathrm{~mA}$ (Figure 5). The interference of barium can be therefore easily suppressed by applying a current of less than $1000 \mathrm{~mA}$ on the filament. The TIMS measurements of mixtures of $10 \mathrm{ng}$ of stable ${ }^{133} \mathrm{Cs}$ with different amounts of $\mathrm{Ba}$ (from $0.1 \mathrm{ng}$ to $100 \mathrm{ng}$ ) showed that when the signal intensity of ${ }^{133} \mathrm{Cs}$ reached $20 \mathrm{~V}$ at a filament current of $930 \mathrm{~mA}$, the count rate at $m / z 135$ was less 


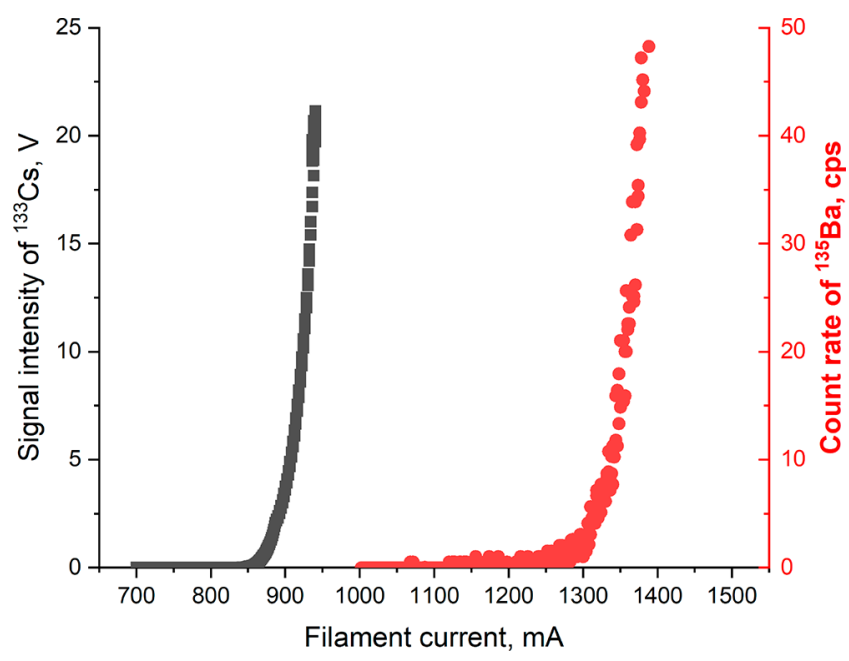

Figure 5. Variation of intensities of ${ }^{133} \mathrm{Cs}$ and ${ }^{135} \mathrm{Ba}$ ion signals with the current applied on the filament for ionization (solution containing $10 \mathrm{ng}$ of cesium, $1 \mathrm{ng}$ of barium, and $10 \mu \mathrm{g}$ of glucose was evaporated at a heating current of $600 \mathrm{~mA}$ on Re filament).

than $0.5 \mathrm{cps}$ for a sample with $10 \mathrm{ng}$ of $\mathrm{Ba}$. This indicates that the influence from $\mathrm{Ba}$ can be significantly suppressed by applying a relatively low filament current for ionization of cesium. It was observed that even for a cesium sample containing $100 \mathrm{ng}$ of $\mathrm{Ba}$, the count rate at $\mathrm{m} / z 135$ was less than $3 \mathrm{cps}$. In this work, the content of $\mathrm{Ba}$ in the final samples was reduced to less than $5 \mathrm{ng}$ by chemical separation using AMP-PAN and ion exchange chromatography; therefore, the isobaric interference from $\mathrm{Ba}$ can be ignored.

Chemical Separation of Cesium from Seawater. Direct measurement of ${ }^{135} \mathrm{Cs}$ and ${ }^{137} \mathrm{Cs}$ in seawater by TIMS is impossible due to the low concentration of radiocesium (1-20 $\mathrm{mBq} / \mathrm{L}^{137} \mathrm{Cs}$ in seawater) and interference from the sample matrix. Therefore, chromatographic separation using APMPAN resin and cation exchange resin (AG 50W- $\times 8$ ) was applied for the separation of cesium from seawater in order to remove all matrix components and the interfering elements such as $\mathrm{Rb}$ and $\mathrm{Ba}$. It was observed that a large fraction of $\mathrm{Cs}$ was coeluted with $\mathrm{Rb}$ via $0.2 \mathrm{M} \mathrm{NH}_{4} \mathrm{NO}_{3}$ solution when a 1 $\mathrm{mL}$ AMP-PAN column was used. A $2 \mathrm{~mL}$ AMP-PAN column $(\varphi 7 \mathrm{~mm} \times 5 \mathrm{~cm})$ was used in this work to enable the removal of $\mathrm{Rb}$ without a significant loss of Cs. Different concentrations of $\mathrm{NH}_{4} \mathrm{NO}_{3}$, i.e., $0.10,0.15$, and $0.20 \mathrm{M}$, as rinse solutions were investigated for removal of $\mathrm{Rb}$ in the AMP-PAN chromatographic separation. The results (Figure 6) show that decontamination factors of $5.9,6.0$, and 7.8 for $\mathrm{Rb}$ were
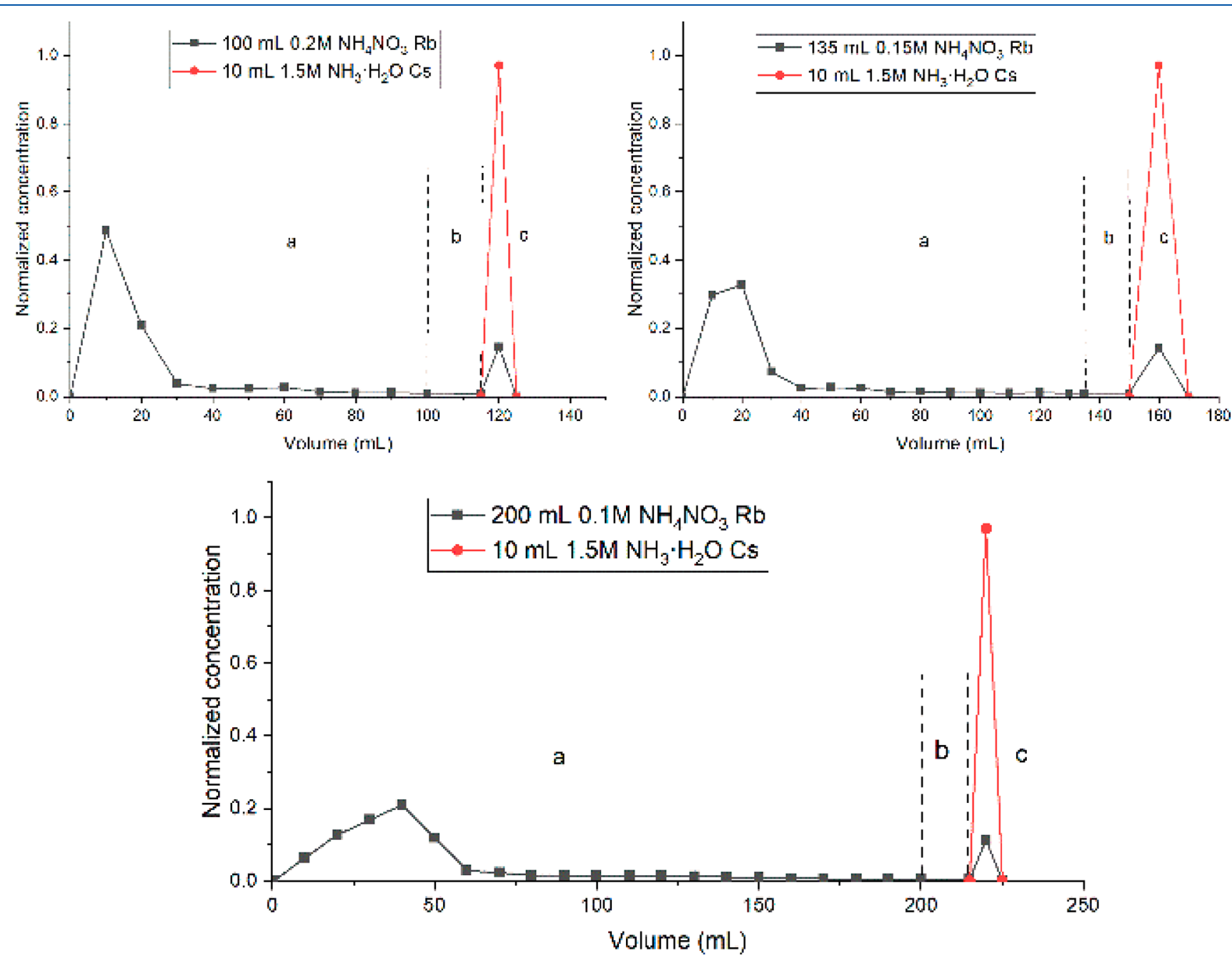

Figure 6. Profiles of $\mathrm{Rb}(100 \mu \mathrm{g})$ and $\mathrm{Cs}(1 \mu \mathrm{g})$ on a $2 \mathrm{~mL}$ AMP-PAN column. (a) Rinsing with $0.10-0.20 \mathrm{M} \mathrm{NH}_{4} \mathrm{NO}_{3}$; (b) rinsing with $15 \mathrm{~mL}$ of $\mathrm{H}_{2} \mathrm{O}$; (c) eluting with $10 \mathrm{~mL}$ of $1.5 \mathrm{M} \mathrm{NH}_{3} \cdot \mathrm{H}_{2} \mathrm{O}$ ). 
obtained by rinsing the column with $100 \mathrm{~mL}$ of $0.20 \mathrm{M}$ $\mathrm{NH}_{4} \mathrm{NO}_{3}, 135 \mathrm{~mL}$ of $0.15 \mathrm{M} \mathrm{NH}_{4} \mathrm{NO}_{3}$, and $200 \mathrm{~mL}$ of $0.10 \mathrm{M}$ $\mathrm{NH}_{4} \mathrm{NO}_{3}$, respectively. Therefore, $200 \mathrm{~mL}$ of $0.10 \mathrm{M} \mathrm{NH}_{4} \mathrm{NO}_{3}$ rinsing followed by an elution using $1.5 \mathrm{M} \mathrm{NH}_{3} \cdot \mathrm{H}_{2} \mathrm{O}$ were employed in the AMP-PAN column separation of Cs.

Although AMP-PAN is a specific resin for the separation of $\mathrm{Cs}$ from a sample matrix, the removal efficiencies of $\mathrm{Rb}$ and other interfering elements such as $\mathrm{Ba}$ and $\mathrm{Mo}$ are not sufficiently high for the TIMS measurement of ${ }^{135} \mathrm{Cs}$. Cation exchange chromatography is often used for further purification of Cs from other cations. ${ }^{1}$ However, the separation of Cs from $\mathrm{Rb}$ is difficult due to their similar properties and behaviors on cation exchange chromatography. The eluting profiles of Cs and $\mathrm{Rb}$ from a cation exchange chromatography column using different concentrations of $\mathrm{HNO}_{3}$ (Figure S3) show a large overlap when $1.5 \mathrm{M} \mathrm{HNO}_{3}$ is used for elution. With a decreasing concentration of $\mathrm{HNO}_{3}$, more solution was needed to elute $\mathrm{Cs}$ and $\mathrm{Rb}$, but a better isolation of $\mathrm{Cs}$ from $\mathrm{Rb}$ was obtained. When the column was eluted with $0.5 \mathrm{M} \mathrm{HNO}_{3}$, and 220-320 mL eluate was collected, a recovery of $70 \%$ for Cs and a decontamination factor of 240 for $\mathrm{Rb}$ were obtained. Although a better removal of $\mathrm{Rb}$ can be obtained by using an even lower concentration of $\mathrm{HNO}_{3}$, a large volume of eluate and long separation time is needed. Considering a $\mathrm{Rb} / \mathrm{Cs}$ mass ratio of 220-400 in seawater ${ }^{33,34}$ and the ignored influence of $\mathrm{Rb}$ when the $\mathrm{Rb} / \mathrm{Cs}$ mass ratio is less than 2, a decontamination factor of more than 1000 for $\mathrm{Rb}$ in seawater will be good enough to eliminate the influence of $\mathrm{Rb}$ on the ionization of Cs in the TIMS measurement of ${ }^{135} \mathrm{Cs}$. Therefore, $0.5 \mathrm{M} \mathrm{HNO}_{3}$ was employed to elute Cs from the cation exchange column. By combining AMP-PAN with cation exchange chromatographic separation, a decontamination factor of more than 1800 for $\mathrm{Rb}$ was achieved, which is more than 3 times higher than the reported values. ${ }^{16,28}$ For TIMS measurement, the $0.5 \mathrm{M} \mathrm{HNO}_{3}$ eluate was evaporated to dryness and redissolved in $10 \mu \mathrm{L}$ of $2 \% \mathrm{HNO}_{3}$ and loaded on the Re filament after being mixed with glucose. Spectra of a mass scan $(m / z$ of $133-138)$ of a real sample (IAEA-375) are presented in Figure S4. No other mass peak except ${ }^{133} \mathrm{Cs}$, ${ }^{135} \mathrm{Cs}$, and ${ }^{137} \mathrm{Cs}$ was observed in this sample, indicating a good separation of cesium from sample matrix and other interfering isotopes (e.g., ${ }^{134} \mathrm{Ba},{ }^{136} \mathrm{Ba},{ }^{138} \mathrm{Ba}$ ).

Recovery of cesium was monitored by measurement of ${ }^{133} \mathrm{Cs}$ in the original and final solution using ICP-MS. The results showed recoveries of $95 \%$ and $70 \%$ in AMP-PAN and AG $50 \mathrm{~W}-\times 8$ chromatographic separation steps, respectively, and an overall recovery of more than $60 \%$ for Cs in the entire procedure. Meanwhile, decontamination factors of $6.0 \times 10^{6}$, $4.2 \times 10^{5}, 3.3 \times 10^{5}$, and $2.1 \times 10^{5}$ were achieved for Ba, Mo, $\mathrm{Sn}$, and $\mathrm{Sb}$, respectively. The total content of $\mathrm{Rb}, \mathrm{Ba}$, and Mo in the final Cs fraction was less than $20 \mathrm{ng}, 3 \mathrm{ng}$, and $5 \mathrm{ng}$, respectively, and $\mathrm{Sb}$ and $\mathrm{Sn}$ presented in the target were $<2 \mathrm{ng}$. The influence from these interfering elements on the measurement of ${ }^{135} \mathrm{Cs}$ and ${ }^{137} \mathrm{Cs}$ by TIMS is therefore eliminated.

Detection Limits of the Method for ${ }^{135} \mathrm{Cs}$ and ${ }^{137} \mathrm{Cs}$. By using a carburized Re filament and glucose as an activator, a stable ${ }^{133} \mathrm{Cs}^{+}$ion intensity of up to $20 \mathrm{~V}$ was obtained for a total load of $10 \mathrm{ng}$ of Cs. Due to the utilization of retarding potential quadrupole (RPQ) in the TIMS, the abundance sensitivities of ${ }^{133} \mathrm{Cs}$ to ${ }^{135} \mathrm{Cs}$ and ${ }^{137} \mathrm{Cs}$ are $<4 \times 10^{-10}$. The count rates at $m / z$ of 135 and 137 in the procedure blanks were measured to be $0.3 \pm 0.2 \mathrm{cps}$. On the basis of these performances, minimum detectable amounts of ${ }^{135} \mathrm{Cs}$ and ${ }^{137} \mathrm{Cs}$ can be estimated to be $5 \times 10^{-18} \mathrm{~g}(0.005 \mathrm{fg})$ using 3 times the standard deviation of the blanks and a measurement sensitivity of $120 \mathrm{cps} / \mathrm{fg}$ for ${ }^{135} \mathrm{Cs}$. For $200 \mathrm{~mL}$ of seawater, the detection limits of the method for ${ }^{135} \mathrm{Cs}$ and ${ }^{137} \mathrm{Cs}$ are calculated to be $4.0 \times 10^{-17} \mathrm{~g} / \mathrm{L}\left(0.13 \mathrm{mBq} / \mathrm{L}\right.$ for $\left.{ }^{137} \mathrm{Cs}\right)$ in consideration of a recovery of $60 \%$ for cesium; this detection limit is about 2 orders of magnitude lower than the reported value using ICP-QQQ-MS ${ }^{10}$ and gamma spectrometry for ${ }^{137}$ Cs. ${ }^{35,36}$

Validation of the Method by Analysis of Certified Materials for ${ }^{135} \mathrm{Cs}$ and ${ }^{137} \mathrm{Cs}$. Two reference materials, seawater IAEA-443 and soil IAEA-375, were analyzed for ${ }^{135} \mathrm{Cs} /{ }^{137} \mathrm{Cs}$ atomic ratios using the developed method. The results (Table 1) indicate that the measured ratios of $1.15 \pm$

Table 1. Comparison of the Analytical Results of ${ }^{135} \mathrm{Cs} /{ }^{137} \mathrm{Cs}$ Atomic Ratios in IAEA Reference Materials with the Reported Values

\begin{tabular}{cll} 
sample & \multicolumn{1}{c}{${ }^{135} \mathrm{Cs} /{ }^{137} \mathrm{Cs}$} & reference \\
IAEA-375 $^{a}$ & $0.30 \pm 0.01(n=5)$ & 27 \\
& $0.30 \pm 0.03(n=3)$ & 24 \\
& $0.31 \pm 0.03(n=3)$ & 11 \\
& $0.27 \pm 0.02(n=1)$ & 10 \\
& $0.32 \pm 0.01(n=1)$ & 37 \\
IAEA-443 $^{b}$ & $0.296 \pm 0.008(n=3)$ & this study \\
& $1.22 \pm 0.16(n=3)$ & 8 \\
& $1.15 \pm 0.07(n=3)$ & this work
\end{tabular}

${ }^{a}$ Decay corrected to April 26, 1986. ${ }^{b}$ Decay corrected to January 1, 2015.

0.07 (decay corrected to January 1, 2015) in IAEA-443 and $0.296 \pm 0.008$ (decay corrected to April 26, 1986) in IAEA375 are in good agreement with the reported values (Table 1). These results demonstrated that the developed method is reliable and accurate for the determination of the ${ }^{135} \mathrm{Cs} /{ }^{137} \mathrm{Cs}$ ratio in a small volume seawater and normal environmental samples.

Determination of ${ }^{135} \mathrm{Cs}$ and ${ }^{137} \mathrm{Cs}$ in Seawater from the Danish Straits, the Baltic Sea, and Greenland West Coast. ${ }^{135} \mathrm{Cs}$ and ${ }^{137} \mathrm{Cs}$ in seawater samples from the Danish Straits, the Baltic Sea, and Greenland west coast were determined using the developed method. The results (Table 2) show that the ${ }^{135} \mathrm{Cs} /{ }^{137} \mathrm{Cs}$ atomic ratios are similar in the seawater collected from the Baltic Sea and the Danish Straits at 0.97-1.18, but lower than that in the Greenland seawater (2.30-2.97), indicating their different sources in these two areas. Besides the global fallout, the Baltic Sea and its surrounding area have received significant deposition of Chernobyl derived radioactive substances including radiocesium; ${ }^{38}$ a high ${ }^{137} \mathrm{Cs}$ level has been observed in the seawater in the Baltic Sea, as well as in the Danish Straits. ${ }^{39}$

The reported ${ }^{135} \mathrm{Cs} /{ }^{137} \mathrm{Cs}$ atomic ratios in the global fallout and Chernobyl accident releases are $3.6 \pm 0.4$ and $0.64 \pm 0.04$ (decay corrected to August 15, 2019), respectively. ${ }^{7,8}$ The ${ }^{135} \mathrm{Cs} /{ }^{137} \mathrm{Cs}$ ratios in seawater from the Danish Straits and the Baltic Sea (0.97-1.18) are higher than the Chernobyl derived radiocesium ratio, but much lower than the global fallout sourced radiocesium ratio. On the basis of two-end model, the contribution of Chernobyl accident derived radiocesium $\left({ }^{135} \mathrm{Cs}\right.$ and ${ }^{137} \mathrm{Cs}$ ) in the water of the Baltic Sea and Danish Straits can be estimated to be $81 \%-89 \%$. On the basis of the long-term 
Table 2. ${ }^{135} \mathrm{Cs} /{ }^{137} \mathrm{Cs}$ Atomic Ratios and ${ }^{137} \mathrm{Cs}$ and ${ }^{135} \mathrm{Cs}$ Concentrations in Seawater from Danish Straits, the Baltic Sea, and Greenland West Coast ${ }^{a}$

\begin{tabular}{|c|c|c|c|c|c|c|c|c|}
\hline sample site & $\begin{array}{l}\text { latitude, } \\
\text { longitude }\end{array}$ & $\begin{array}{c}\text { Cs } \\
\text { concentration } \\
\left(\mu \mathrm{g} \mathrm{L}^{-1}\right)\end{array}$ & $\begin{array}{l}{ }^{137} \mathrm{Cs} /{ }^{133} \mathrm{Cs} \\
\text { atomic ratio } \\
\qquad\left(10^{-8}\right)\end{array}$ & $\begin{array}{l}{ }^{135} \mathrm{Cs} /{ }^{133} \mathrm{Cs} \\
\text { atomic ratio } \\
\qquad\left(10^{-8}\right)\end{array}$ & $\begin{array}{l}{ }^{135} \mathrm{Cs} /{ }^{137} \mathrm{Cs} \\
\text { atomic ratio }\end{array}$ & $\begin{array}{c}{ }^{137} \mathrm{Cs} \\
\text { concentration }^{b} \\
\left(\mathrm{mBq} \mathrm{L}^{-1}\right)\end{array}$ & $\begin{array}{c}{ }^{137} \mathrm{Cs} \\
\text { concentration }^{c} \\
\left(\mathrm{mBq} \mathrm{L} \mathrm{L}^{-1}\right)\end{array}$ & $\begin{array}{c}{ }^{135} \mathrm{Cs} \\
\text { concentration }^{b} \\
\left(\mu \mathrm{Bq} / \mathrm{m}^{3}\right)\end{array}$ \\
\hline Møen & $\begin{array}{l}54^{\circ} 57^{\prime}, \\
12^{\circ} 41^{\prime}\end{array}$ & $0.43 \pm 0.01$ & $1.81 \pm 0.17$ & $1.78 \pm 0.17$ & $0.98 \pm 0.08$ & $23.4 \pm 2.2$ & $21.8 \pm 0.6$ & $301 \pm 28$ \\
\hline Sundet S & $\begin{array}{l}55^{\circ} 25^{\prime} \\
12^{\circ} 36^{\prime}\end{array}$ & $0.82 \pm 0.01$ & $0.80 \pm 0.08$ & $0.79 \pm 0.08$ & $0.99 \pm 0.15$ & $19.6 \pm 2.0$ & $20.1 \pm 0.7$ & $255 \pm 26$ \\
\hline Kattegat & $\begin{array}{l}56^{\circ} 39^{\prime}, \\
12^{\circ} 00^{\prime}\end{array}$ & $0.29 \pm 0.01$ & $1.79 \pm 0.42$ & $2.11 \pm 0.50$ & $1.18 \pm 0.12$ & $15.5 \pm 3.7$ & $11.6 \pm 0.4$ & $241 \pm 57$ \\
\hline Hesselø & $\begin{array}{l}56^{\circ} 10^{\prime} \\
11^{\circ} 47^{\prime}\end{array}$ & $0.22 \pm 0.01$ & $1.42 \pm 0.18$ & $1.57 \pm 0.20$ & $1.11 \pm 0.21$ & $9.40 \pm 1.22$ & $9.96 \pm 0.65$ & $137 \pm 18$ \\
\hline Hesselø & $\begin{array}{l}56^{\circ} 10^{\prime}, \\
11^{\circ} 47^{\prime}\end{array}$ & $1.17 \pm 0.02$ & $0.51 \pm 0.09$ & $0.50 \pm 0.09$ & $0.97 \pm 0.27$ & $18.0 \pm 3.2$ & $13.3 \pm 0.6$ & $229 \pm 41$ \\
\hline Baltic Sea & $\begin{array}{l}54^{\circ} 30^{\prime}, \\
14^{\circ} 40^{\prime}\end{array}$ & $0.42 \pm 0.01$ & $2.09 \pm 0.27$ & $2.42 \pm 0.32$ & $1.16 \pm 0.13$ & $26.6 \pm 3.5$ & $25.7 \pm 1.1$ & $401 \pm 53$ \\
\hline Greenland & $\begin{array}{l}63^{\circ} 52^{\prime}, \\
52^{\circ} 22^{\prime}\end{array}$ & $0.61 \pm 0.01$ & $0.117 \pm 0.031$ & $0.346 \pm 0.093$ & $2.97 \pm 0.86$ & $2.12 \pm 0.57$ & $1.89 \pm 0.18$ & $82.6 \pm 22.2$ \\
\hline Greenland & $\begin{array}{l}70^{\circ} 47^{\prime} \\
58^{\circ} 31^{\prime}\end{array}$ & $0.75 \pm 0.01$ & $0.074 \pm 0.022$ & $0.170 \pm 0.050$ & $2.30 \pm 0.85$ & $1.66 \pm 0.49$ & $1.56 \pm 0.23$ & $50.1 \pm 14.8$ \\
\hline
\end{tabular}

${ }^{a}$ Reference date is August 15, 2019. ${ }^{b}$ Results obtained in this work using the measured ${ }^{137} \mathrm{Cs} /{ }^{133} \mathrm{Cs}$ and ${ }^{135} \mathrm{Cs} /{ }^{133} \mathrm{Cs}$ ratios by TIMS and ${ }^{133} \mathrm{Cs}$ concentration in seawater measured by ICP-MS. ${ }^{c}$ Results of $\gamma$ measurement of the concentrated Cs in $50 \mathrm{~g}$ of AMP from $45 \mathrm{~L}$ of seawater.

monitoring of ${ }^{137} \mathrm{Cs}$ in the Baltic Sea and Danish Straits, the contributions of Chernobyl accident and global fallout have been estimated to be $80 \%$ and $16 \%$ in this region. ${ }^{40}$ Our estimation is similar to this value; the slight difference and variation might be attributed to the marine discharges of the reprocessing plants at La Hague and Sellafield that entered the Baltic Sea through the Danish Straits and were an important source of ${ }^{137} \mathrm{Cs}$ in the Danish Straits and south of the Baltic Sea in the 1970s until early 1980s. Because of the significantly reduced discharges of ${ }^{137} \mathrm{Cs}$ from these reprocessing plants since the 1980s, the contribution of this source is limited in the present seawater in the Baltic Sea and the Danish Straits.

The measured ${ }^{135} \mathrm{Cs} /{ }^{137} \mathrm{Cs}$ atomic ratios in the seawater from the Greenland west coast are $2.97 \pm 0.86$ and $2.30 \pm$ 0.85 , which is lower than the global fallout ratio $(3.6 \pm 0.4)$, indicating that besides the global fallout of nuclear weapons tests as the dominant source, other sources also contributed to ${ }^{137} \mathrm{Cs}$ and ${ }^{135} \mathrm{Cs}$ in the Greenland west coast seawater. These sources should be the discharges from the reprocessing plants (with a ${ }^{135} \mathrm{Cs} /{ }^{137} \mathrm{Cs}$ atomic ratio of $1.36 \pm 0.17$ from Sellafield reprocessing plant, decay corrected to August 15,2019$)$ as well as the Chernobyl accident releases (with a ${ }^{135} \mathrm{Cs} /{ }^{137} \mathrm{Cs}$ atomic ratio of $0.64 \pm 0.04$ ). Transport of the marine discharges from the reprocessing plants at La Hague and Sellafield to the Greenland Sea and to the Greenland west coast has been observed via the measurement of ${ }^{129} \mathrm{I}$ and ${ }^{99} \mathrm{Tc}$, which are highly discharged from European reprocessing plants. ${ }^{41,42}$

The ${ }^{137} \mathrm{Cs}$ concentrations (Table 2) in seawater were calculated based on the measured ${ }^{137} \mathrm{Cs} /{ }^{133} \mathrm{Cs}$ atomic ratios in this work and the ${ }^{133} \mathrm{Cs}$ concentration measured by ICP-MS. Meanwhile, the ${ }^{137} \mathrm{Cs}$ concentrations in the same water samples were also determined by HPGe gamma spectrometry after adsorption of cesium with $50 \mathrm{~g}$ of AMP powder from 45 $\mathrm{L}$ of seawater. The results measured by TIMS are in good agreement with those measured by gamma spectrometry, further confirming the reliability of the developed method for the determination of ${ }^{137} \mathrm{Cs}$. However, a much smaller volume of seawater $(200 \mathrm{~mL})$ and less analytical time (2 days for sample preparation and measurement) are needed in the developed method compared to the gamma spectrometry (45 $\mathrm{L}$ of seawater and 4-5 days of analytical time). In addition, the developed mass spectrometry method can give not only the ${ }^{135} \mathrm{Cs} /{ }^{137} \mathrm{Cs}$ ratio but also the concentrations of ${ }^{137} \mathrm{Cs}$ and ${ }^{135} \mathrm{Cs}$, therefore providing the level, distribution, and source of radiocesium in the investigated seas, as well as the contribution of each source.

\section{CONCLUSIONS}

A method of chromatographic separation in combination with TIMS measurement was developed and successfully applied for determination of ${ }^{135} \mathrm{Cs}$ and ${ }^{137} \mathrm{Cs}$ concentrations and ${ }^{135} \mathrm{Cs} /{ }^{137} \mathrm{Cs}$ atomic ratios in small volume seawater $(<200$ $\mathrm{mL})$; the following achievements were reached: (1) An overall decontamination factor of 1800 for $\mathrm{Rb}$ was achieved by using an AMP-PAN combined with a cation exchange chromatographic separation. (2) The ionization efficiency of cesium in the TIMS was significantly improved from less than $0.5 \%$ up to $50 \%$ by using $10 \mu \mathrm{g}$ of glucose as an activator, carburized Re filament, and a $600 \mathrm{~mA}$ heating current for target preparation. This ensures obtaining a constantly high intensity of the $\mathrm{Cs}^{+}$ ion beam for sensitive and reliable measurement of cesium isotopes for a long time up to $180 \mathrm{~min}$ for a $10 \mathrm{ng}$ Cs target. (3) With the developed method, a detection limit of $4.0 \times$ $10^{-17} \mathrm{~g} / \mathrm{L}$ for ${ }^{135} \mathrm{Cs}$ and ${ }^{137} \mathrm{Cs}$ (corresponding to $1.7 \mu \mathrm{Bq} / \mathrm{m}^{3}$ for ${ }^{135} \mathrm{Cs}$ ) was achieved for a $200 \mathrm{~mL}$ seawater sample, and the analytical method was verified by analysis of seawater reference material IAEA-443. (4) The developed method has been successfully applied to determine ${ }^{135} \mathrm{Cs}$ and ${ }^{137} \mathrm{Cs}$ in seawater from the Danish Straits, the Baltic Sea, and Greenland west coast, with ${ }^{137} \mathrm{Cs}$ concentrations down to $1.56 \mathrm{mBq} / \mathrm{L}$. The ${ }^{135} \mathrm{Cs} /{ }^{137} \mathrm{Cs}$ atomic ratios in the Baltic Sea and Danish Straits (0.97-1.18) are much lower than that in the Greenland west coast $(2.30-2.97)$. On the basis of the reported ${ }^{135} \mathrm{Cs} /{ }^{137} \mathrm{Cs}$ ratios from different sources, it was estimated that more than $81 \%$ of the radiocesium in the Baltic Sea is originated from the Chernobyl accident, which agrees with the estimated value from the long-term measurement of ${ }^{137} \mathrm{Cs}$ in the Baltic Sea. (5) The developed method is suitable for accurate determination of ${ }^{135} \mathrm{Cs}$ and ${ }^{137} \mathrm{Cs}$ in a small volume of seawater $(<200 \mathrm{~mL})$ for not only routine monitoring but also identification of the 
sources of radiocesium pollution and tracing transport pathway of polluted water masses.

\section{ASSOCIATED CONTENT}

\section{SI Supporting Information}

The Supporting Information is available free of charge at https://pubs.acs.org/doi/10.1021/acs.analchem.0c00688.

Four figures, i.e. sampling sites, chemical procedure for separation of cesium from seawater, elution profiles of $\mathrm{Cs}$ and $\mathrm{Rb}$ from a cation exchange chromatographic column, and spectra of mass scan $(\mathrm{m} / z 133-138)$ of a prepared sample for measurement of cesium isotopes (PDF)

\section{AUTHOR INFORMATION}

\section{Corresponding Author}

Xiaolin Hou - Technical University of Denmark, Department of Environmental Engineering, Roskilde DK-4000, Denmark; ๑ orcid.org/0000-0002-4851-4858; Email: xiho@dtu.dk; Fax: 4546775357

\section{Authors}

Liuchao Zhu - Technical University of Denmark, Department of Environmental Engineering, Roskilde DK-4000, Denmark

Changkun Xu - China Institute of Atomic Energy, Beijing 102413, China

Jixin Qiao - Technical University of Denmark, Department of Environmental Engineering, Roskilde DK-4000, Denmark; (1) orcid.org/0000-0001-5409-4274

Yonggang Zhao - China Institute of Atomic Energy, Beijing 102413, China

Guorong Liu - China Institute of Atomic Energy, Beijing 102413, China

Complete contact information is available at:

https://pubs.acs.org/10.1021/acs.analchem.0c00688

\section{Author Contributions}

The manuscript was written through contributions of all authors. L.Z. designed and implemented the experiment and drafted the manuscript. C.X. implemented the TIMS measurement. X.H. designed the overall research. X.H. and J.Q. designed the experiment and revised the manuscript. Z.Y. and L.G. revised the manuscript. All authors have given approval to the final version of the manuscript.

\section{Notes}

The authors declare no competing financial interest.

\section{ACKNOWLEDGMENTS}

The invaluable assistance from Dr. Lili Li and Tongxing Wang from China Institute of Atomic Energy in the measurement of cesium isotopes by TIMS and the useful suggestions from Dr. Xiaoyan Jiang and Xinghong Zhao are acknowledged.

\section{REFERENCES}

(1) Russell, B. C.; Croudace, I. W.; Warwick, P. E. Anal. Chim. Acta 2015, 890, 7-20.

(2) Masson, O.; Bieringer, J.; Brattich, E.; Dalheimer, A.; Estier, S.; Penev, I.; Ringer, W.; Schlosser, C.; Steinkopff, T.; Steinmann, P.; Tositti, L.; Van Beek, P.; Vismes-Ott, A. d. J. Environ. Radioact. 2016, 162-163, 14-22.

(3) Martin, J. M.; Thomas, A. J. J. Environ. Radioact. 1990, 11, 105139.
(4) Rostan, J. C.; Juget, J.; Brun, A. M. Sci. Total Environ. 1997, 193, 251-262.

(5) Kershaw, P.; Baxter, A. Deep Sea Res., Part II 1995, 42, 14131448.

(6) Bailly du Bois, P.; Laguionie, P.; Boust, D.; Korsakissok, I.; Didier, D.; Fievet, B. J. Environ. Radioact. 2012, 114, 2-9.

(7) Lee, T.; Teh-Lung, K.; Hsiao-Ling, L.; Ju-Chin, C. Geochim. Cosmochim. Acta 1993, 57, 3493-3497.

(8) Snow, M. S.; Snyder, D. C. J. Environ. Radioact. 2016, 151, 258263.

(9) Zheng, J.; Tagami, K.; Bu, W.; Uchida, S.; Watanabe, Y.; Kubota, Y.; Fuma, S.; Ihara, S. Environ. Sci. Technol. 2014, 48, 5433-5438.

(10) Yang, G.; Tazoe, H.; Yamada, M. Anal. Chim. Acta 2016, 908, $177-184$

(11) Zheng, J.; Bu, W.; Tagami, K.; Shikamori, Y.; Nakano, K.; Uchida, S.; Ishii, N. Anal. Chem. 2014, 86, 7103-7110.

(12) Zheng, J.; Cao, L.; Tagami, K.; Uchida, S. Anal. Chem. 2016, $88,8772-8779$.

(13) Ohno, T.; Muramatsu, Y. J. Anal. At. Spectrom. 2014, 29, 347351.

(14) Shibahara, Y.; Kubota, T.; Fujii, T.; Fukutani, S.; Ohta, T.; Takamiya, K.; Okumura, R.; Mizuno, S.; Yamana, H. J. Nucl. Sci. Technol. 2014, 51, 575-579.

(15) Yang, G.; Tazoe, H.; Yamada, M. Sci. Rep. 2016, 6, 24119.

(16) Bu, W.; Tang, L.; Liu, X.; Wang, Z.; Fukuda, M.; Zheng, J.;

Aono, T.; Hu, S.; Wang, X. J. Anal. At. Spectrom. 2019, 34, 301-309.

(17) Shibahara, Y.; Kubota, T.; Fujii, T.; Fukutani, S.; Takamiya, k.; Konno, M.; Mizuno, S.; Yamana, H. J. Nucl. Sci. Technol. 2017, 54, 158-166.

(18) Asai, S.; Ohata, M.; Hanzawa, Y.; Horita, T.; Yomogida, T.; Kitatsuji, Y. Anal. Chem. 2020, 92, 3276.

(19) Stamm, H. J. Radioanal. Nucl. Chem. 1973, 14, 367-373.

(20) Russell, B. C.; Warwick, P. E.; Croudace, I. W. Anal. Chem. 2014, 86, 11890-11896.

(21) Russell, B. C.; Croudace, I. W.; Warwick, P. E.; Milton, J. A. Anal. Chem. 2014, 86, 8719-8726.

(22) Song, M.; Probst, T.; Berryman, N. Fresenius' J. Anal. Chem. 2001, 370, 744-751.

(23) Karam, L. R.; Pibida, L.; McMahon, C. A. Appl. Radiat. Isot. 2002, 56, 369-374.

(24) Taylor, V. F.; Evans, R. D.; Cornett, R. J. J. Environ. Radioact. 2008, 99, 109-118.

(25) Delmore, J. E.; Snyder, D. C.; Tranter, T.; Mann, N. R. J. Environ. Radioact. 2011, 102, 1008-1011.

(26) Snow, M. S.; Snyder, D. C.; Delmore, J. E. Rapid Commun. Mass Spectrom. 2016, 30, 523-532.

(27) Snow, M. S.; Snyder, D. C.; Mann, N. R.; White, B. M. Int. J. Mass Spectrom. 2015, 381-382, 17-24.

(28) Dunne, J. A.; Richards, D. A.; Chen, H. W. Talanta 2017, 174, 347-356.

(29) Snow, M. S.; Snyder, D. C.; Clark, S. B.; Kelley, M.; Delmore, J. E. Environ. Sci. Technol. 2015, 49, 2741-2748.

(30) Jakopič, R.; Richter, S.; Kuhn, H.; Aregbe, Y. J. Anal. At. Spectrom. 2010, 25, 815-821.

(31) Kraiem, M.; Mayer, K.; Gouder, T.; Seibert, A.; Wiss, T.; Thiele, H.; Hiernaut, J.-P. Int. J. Mass Spectrom. 2010, 289, 108-118.

(32) Bu, W.; Zheng, J.; Liu, X.; Long, K.; Hu, S.; Uchida, S. Spectrochim. Acta, Part B 2016, 119, 65-75.

(33) Riley, J. P.; Tongudai, M. Chem. Geol. 1966, 1, 291-294.

(34) Bolter, E.; Turekian, K. K.; Schutz, D. F. Geochim. Cosmochim. Acta 1964, 28, 1459-1466.

(35) Hirose, K.; Aoyama, M.; Igarashi, Y.; Komura, K. J. Radioanal. Nucl. Chem. 2008, 276, 795-798.

(36) van Put, P; Debauche, A; De Lellis, C; Adam, V J. Environ. Radioact. 2004, 72, 177-186.

(37) Cao, L.; Zheng, J.; Tsukada, H.; Pan, S.; Wang, Z.; Tagami, K.; Uchida, S. Talanta 2016, 159, 55-63.

(38) Povinec, P. P; Bailly du Bois, P.; Kershaw, P. J; Nies, H.; Scotto, P. Deep Sea Res., Part II 2003, 50, 2785-2801. 
(39) Qiao, J.; Andersson, K.; Nielsen, S. Chemosphere 2020, 244, 125595.

(40) Ikaheimonen, T. K.; Outola, I.; Vartti, V.; Kotilainen, P. J. Radioanal. Nucl. Chem. 2009, 282, 419-425.

(41) Dahlgaard, H. J. Environ. Radioact. 1994, 25, 37-55.

(42) Hou, X.; Dahlgaard, H.; Nielsen, S. P. Estuarine, Coastal Shelf Sci. 2000, 51, 571-584. 